\title{
USGS Information Technology Strategic Plan: Fiscal Years 2007-2011
}

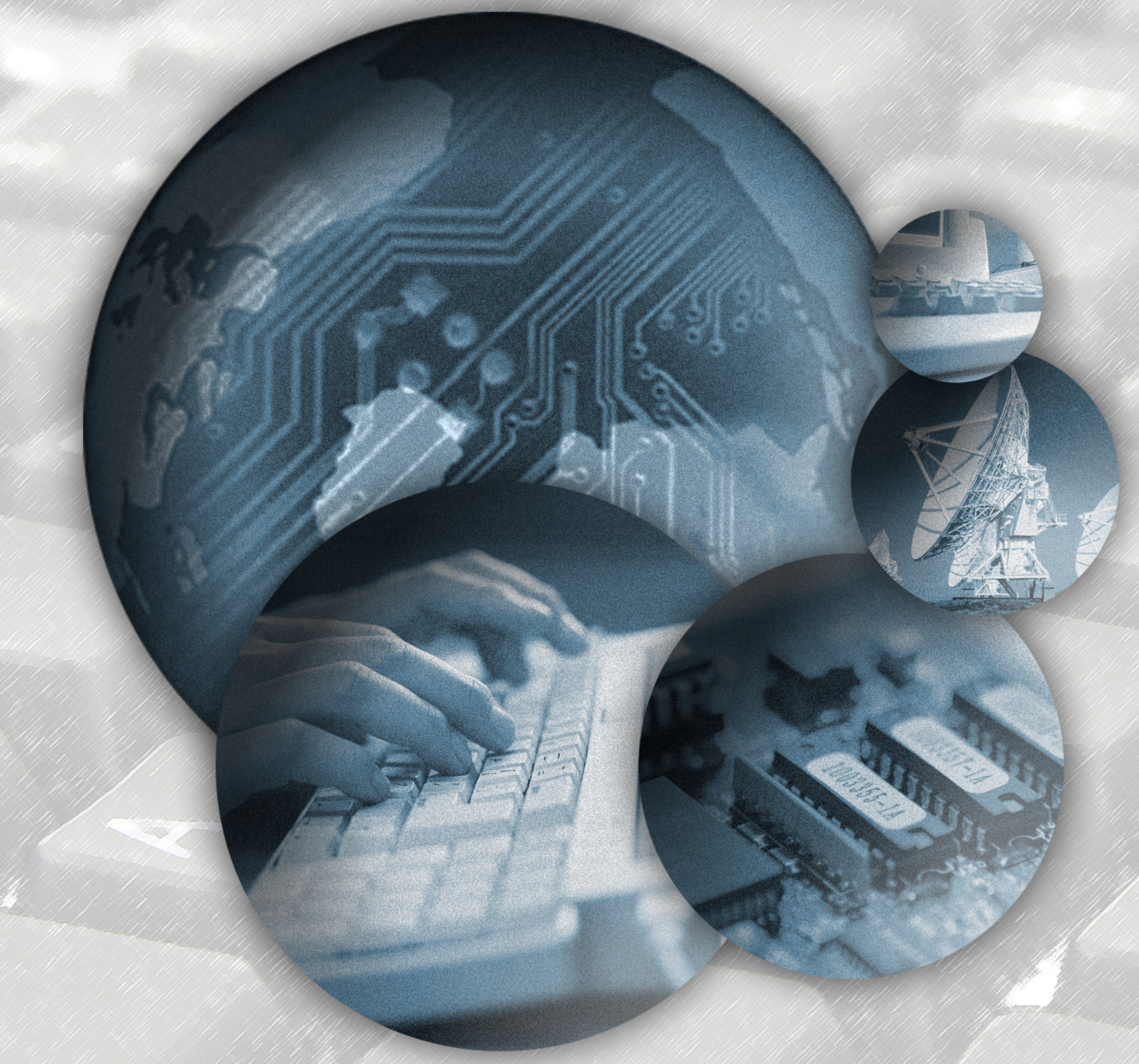

Circular 1304

U.S. Department of the Interior

U.S. Geological Survey 
This page has been left blank intentionally. 


\section{USGS Information Technology Strategic Plan: Fiscal Years 2007-2011}

Circular 1304 


\title{
U.S. Department of the Interior \\ DIRK KEMPTHORNE, Secretary
}

\author{
U.S. Geological Survey \\ Mark D. Myers, Director
}

U.S. Geological Survey, Reston, Virginia: 2006

For more information on the USGS--the Federal source for science about the Earth, its natural and living resources, natural hazards, and the environment:

World Wide Web: http://www.usgs.gov

Telephone: 1-888-ASK-USGS

Any use of trade, product, or firm names is for descriptive purposes only and does not imply endorsement by the U.S. Government.

Although this report is in the public domain, permission must be secured from the individual copyright owners to reproduce any copyrighted materials contained within this report.

Suggested citation:

U.S. Geological Survey, 2006, USGS Information Technology Strategic Plan: Fiscal Years 2007-2011:

U.S. Geological Survey Circular 1304, 19 p., online only. 


\section{Contents}

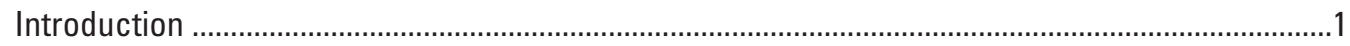

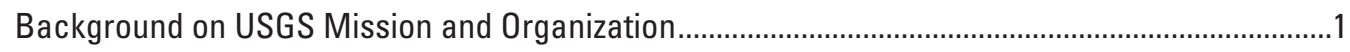

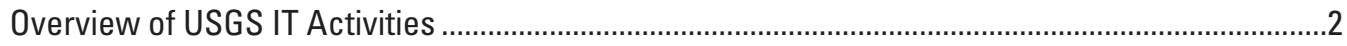

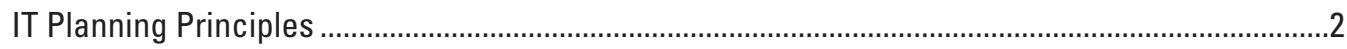

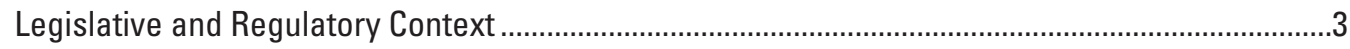

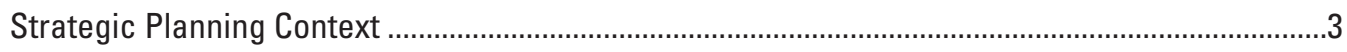

IT Strategic Goals and Objectives .....................................................................................

Strategic Goal 1: Create the Information Technology Component of the Integrated Information Environment.............................................................................

Strategic Goal 2: Create the Information Management and Services Component of the Integrated Information Environment.............................................................7

Strategic Goal 3: Create the Information Policy and Governance Component of the Integrated Information Environment...........................................................10

Strategic Goal 4: Create the Environmental Information Science Component of the Integrated Information Environment. ............................................................11

Appendix I. DOI's Response to M-06-02 Improving Public Access to and Dissemination of Government Information Using the FEA Data Reference Model.........................12

Appendix II. List of USGS Major IT Systems that are Certified and Accredited...........................16

Appendix III. FY2006 USGS IT Investment Portfolio (as of August 14, 2006)................................18 
This page has been left blank intentionally. 


\section{USGS Information Technology Strategic Plan: Fiscal Years 2007-2011}

\section{Introduction}

The acquisition, management, communication, and long-term stewardship of natural science data, information, and knowledge are fundamental mission responsibilities of the U.S. Geological Survey (USGS). USGS scientists collect, maintain, and exchange raw scientific data and interpret and analyze it to produce a wide variety of science-based products. Managers throughout the Bureau access, summarize, and analyze administrative or business-related information to budget, plan, evaluate, and report on programs and projects. Information professionals manage the extensive and growing stores of irreplaceable scientific information and knowledge in numerous databases, archives, libraries, and other digital and nondigital holdings. Information is the primary currency of the USGS, and it flows to scientists, managers, partners, and a wide base of customers, including local, State, and Federal agencies, private sector organizations, and individual citizens.

Supporting these information flows is an infrastructure of computer systems, telecommunications equipment, software applications, digital and nondigital data stores and archives, technical expertise, and information policies and procedures. This infrastructure has evolved over many years and consists of tools and technologies acquired or built to address the specific requirements of particular projects or programs. Developed independently, the elements of this infrastructure were typically not designed to facilitate the exchange of data and information across programs or disciplines, to allow for sharing of information resources or expertise, or to be combined into a Bureauwide and broader information infrastructure. The challenge to the Bureau is to wisely and effectively use its information resources to create a more Integrated Information Environment that can reduce costs, enhance the discovery and delivery of scientific products, and improve support for science.

This Information Technology Strategic Plan for the USGS outlines key information technology (IT) strategic goals and objectives that will support the Bureau's science mission, while also aligning with the Department of the Interior (DOI) IT Strategic Plan and the DOI Government Performance and Results Act (GPRA) Strategic Plan.

\section{Background on USGS Mission and Organization}

The USGS serves the Nation by providing reliable scientific information to describe and understand the Earth; minimize loss of life and property from natural disasters; manage water, biological, energy, and mineral resources; and enhance and protect our quality of life. Field investigations, direct observations of natural science processes and phenomena, and monitoring and data collection across four major earth science disciplines (Biology, Geography, Geology, and Hydrology) are the scientific hallmarks of the USGS. The USGS has the primary Federal responsibility for monitoring and issuing warnings for earthquakes, volcanic eruptions, landslides, and geomagnetic (solar) storms and works closely with the National Weather Service in providing the hydrologic information used to forecast floods; the National Oceanic and Atmospheric Administration in monitoring coastal erosion and tsunamis; and the Interagency Fire Center to support wildland fire management.

With a total (appropriated and reimbursable) annual budget of more than $\$ 1$ billion, the USGS leverages its resources and expertise in partnership with more than 2,000 agencies of State, local, and tribal governments, the academic community, other Federal agencies, nongovernmental organizations, and the private sector. The approximately 10,000 scientists, technicians, and support staff of the USGS are located in over 400 offices in every State and in several foreign countries. USGS Headquarters is located in Reston, Va., and comprises the management and leadership of the scientific and administrative programs of the Bureau. A regional structure delivers science in the field.

In FY2005, the USGS established the Enterprise Information Program (EIP) to serve as the primary vehicle for planning and pursuing broad Bureau-level information goals and objectives and ensuring compliance with specific directives and mandates from DOI, the Office of Management and Budget (OMB), Congress and its Government Accountability Office (GAO), and with the E-Government component of the President's Management Agenda. 
In addition to the Bureau-level investments in information resources administered through the EIP, individual USGS science disciplines, offices, and programs also make investments in data and information assets, IT systems and applications, and workforce. Because a significant portion of the Bureau's information assets and resources are outside of the EIP, development of a more integrated information environment for USGS as a whole depends on communication, cooperation, and collaboration across many USGS programs.

\section{Overview of USGS IT Activities}

Within the USGS, the duties, functions, and responsibilities of the Chief Information Officer are fulfilled by the Geospatial Information Officer (GIO), who also serves administratively as the Associate Director for Geospatial Information. The GIO is responsible for overall policy direction, management, and oversight of Bureau-level IT infrastructure and systems acquisition, development, and management; IT capital planning and investment management; information security; human capital for managing information resources; E-Government initiatives and innovation; strategic planning for information resources; enterprise architecture and advancing the Federal Enterprise Architecture (FEA); records management; privacy; and information collection, dissemination, access, and delivery. This suite of responsibilities is consistent with those of other Federal government agencies and leading private-sector entities in its comprehensive approach to information assets and is in accord with recommendations of the GAO and DOI Secretarial Order 3244.

A Regional Geospatial Information Officer (RGIO) guides and oversees the implementation of IT systems and technology in each of the USGS's three geographic regions. The RGIOs report to their respective Regional Directors to ensure linkage in support of regional science priorities and are matrixed to the Bureau's GIO to ensure the effective and consistent implementation of enterprise IT operations in the field. ${ }^{1}$

\footnotetext{
${ }^{1}$ The GIO is also responsible for management of the National Geospatial Program (NGP), which includes leadership of USGS topographic mapping (The National Map), the Secretariat of the Federal Geographic Data Committee, the Geospatial One-Stop Project, and other national and international-level geospatial coordination activities. Strategic planning for the NGP is addressed within the NGP Plan for Action and is therefore not included within the scope of this IT Strategic Plan.
}

\section{IT Planning Principles}

All USGS IT strategic and annual program planning adheres to the following three planning principles:

Life-cycle approach to information: A life-cycle approach to stewardship of the USGS's data and information holdings considers all current and future uses and requirements with the intent of minimizing the total costs of acquisition, use, and maintenance and maximizing longterm value. Data and information originate in monitoring, scientific inquiry and analysis, operations, and other activities in the Bureau and are subsequently stored, manipulated, and transmitted (and sometimes lost). In many cases, they become - or should become - part of long-term scientific datasets and (or) official records, subject to specific storage and archival requirements. Data and information are accessed in later years for many reasons including, most importantly, for research purposes but also for documenting administrative and financial records and for responding to legal actions such as Freedom of Information Act (FOIA) requests.

Interoperability: The value of data and information can be increased if they are collected once and used many times. Similarly, information tools and systems can be made more valuable if they can be used for multiple purposes or if they can be combined with other tools and systems to perform new and unanticipated tasks. In general, supporting more integrated or interoperable approaches to data and information collection, management, and delivery will increase the value of USGS science-based products, reduce the costs of operations, and enhance the ability to integrate science and management across disciplinary lines. The ability to develop and use data, technologies, and systems in more interoperable ways depends to a large extent on an organization's commitment to the use of widely available open standards, such as those developed by the Federal Geographic Data Committee (FGDC), the Open Geospatial Consortium (OGC), the International Standards Organization (ISO), the World Wide Web Consortium (W3C), and other organizations.

Collaboration: Collaboration on information activities and investments among USGS science programs, disciplines, and regions and with Federal, State, local, and nongovernmental organizations will generate multiple benefits. Costs, both developmental and operational, can be shared; new methods and technologies can be more quickly identified and integrated into scientific activities; specialized technical expertise can be leveraged to help support different projects; science program needs can be more effectively and efficiently communicated to administrators, developers, and vendors; and new research activities, both inter- and intradisciplinary, can be enabled. 


\section{Legislative and Regulatory Context}

There are numerous legislative, regulatory, and administrative requirements that impact information technology and management within the USGS. These include:

- FY2002 President's Management Agenda (PMA)

- E-Government Act of 2002

- Federal Information Security Management Act (FISMA) of 2002

- Office of Management and Budget (OMB) Federal Enterprise Architecture Program

- IT Management Reform Act of 1996 (ITMRA) or Clinger-Cohen Act

- Federal Acquisition Reform Act of 1996 (FARA)

- Government Paperwork Elimination Act 1998 (GPEA)

- Government Management Reform Act of 1994 (GMRA)

- Federal Acquisition Streamlining Act of 1994 (FASA)

- Paperwork Reduction Act of 1995 (PRA)

- Presidential Decision Directive 63 (PDD-63)

- Government Performance and Results Act of 1993 (GPRA)

- Chief Financial Officers Act of 1990 (CFO Act)

- Privacy Act of 1974

- Freedom of Information Act (FOIA)

- Federal Records Act (FRA)

- Federal Financial Management Improvement Act (FFMIA)

- Section 508, Rehabilitation Act of 1998 (29 U.S.C. 794d)

- Rehabilitation Act Amendments (Section 508)

- Homeland Security Presidential Directive (HSPD) 12

- OMB Circular A-11: Preparation, Submission and Execution of the Budget

- OMB Circular A-130: Management of Federal Information Resources
- OMB Circular A-16: Coordination of Geographic Information and Related Spatial Data Activities

- OMB Circular A-76: Performance of Commercial Activities

- OMB M-06-02: Improving Public Access to and Dissemination of Government Information Using the FEA Data Reference Model (see Appendix I)

\section{Strategic Planning Context}

Under the DOI GPRA Strategic Plan, USGS science and information management activities support the Resource Use, Resource Protection, and Serving Communities mission areas as well as the Management Excellence component.

As part of the USGS's established program planning process, the Bureau developed a strategic 5-year program plan for the Enterprise Information Program in FY2005. Within the USGS, this plan is used to define key program objectives and priorities for the Enterprise Information Program and to identify linkages between this program, other USGS programs in science and administration, and the Bureau's 10-year Science Strategy. The Bureau also administers an annual program planning process that is used to develop specific annual plans of work (and to allocate resources) in order to accomplish the goals and objectives of the 5-year program plans.

The Department's IT Strategic Plan for FY2007-012 identifies seven long-term strategic goals specifically for the information technology arena. This USGS IT Strategic Plan provides a key linkage between the goals and objectives outlined in the Enterprise Information Program Plan and the long-term goals of the DOI IT Strategic Plan.

\section{IT Strategic Goals and Objectives}

The USGS is working to develop an Integrated Information Environment that will enhance our scientific mission capabilities and meet the needs of our customers now and in the future. The integrated information environment will consist of an infrastructure of hardware, software, standards, procedures, capabilities, and processes that delivers valuable tools, services, and capabilities in ways that are predictable, cost effective, and adaptable. It will align with and support the IT strategy of the Department of the Interior. 


\section{Strategic Goal 1: Create the Information Technology Component of the Integrated Information Environment.}

Information technology is the foundation for an integrated USGS information environment whose specific IT requirements are derived from the mission and business needs of the organization. Centralization of the planning, acquisition, and operation of the USGS computing infrastructure under the GIO has resulted in improvements, including enhanced internal controls and operational efficiencies, over the previous decentralized approach. An Enterprise Architecture (EA), discussed below, provides the overarching framework for this goal, and its development is the first of five objectives. Four additional objectives address information security, telecommunications, the computing infrastructure, and information technology support services.

This Goal links to the following long-term goals from DOI IT Strategic Plan:

1. Enterprise Architecture: Leverage EA to improve DOI's mission performance and realize its strategic goals and objectives.

2. IT Security: Protect the availability, confidentiality, and integrity of DOI's IT resources.

3. IT Infrastructure: Provide world-class enterprise solutions-improving the quality, accessibility, and sharing information between DOI and its customers.

\section{Objective A: Develop an Enterprise Architecture for the USGS.}

The USGS is aligned with the Federal EA and the DOI EA and is actively participating in the DOI Enterprise IT Transformation activities, including the Enterprise Services Network, Active Directory, Enterprise Hardware and Software Acquisitions, Enterprise Messaging, and E-Authentication (HSPD-12). The USGS is, in turn, responsible for development and maintenance of a Bureauspecific EA that "nests" within the broader DOI architecture. Work under this objective will enable the USGS to achieve DOI-prescribed EA maturity levels, as defined in the OMB Enterprise Architecture Maturity Framework.

Key tasks for FY2007-2008 include:

- Coordinate and support the USGS EA in its relation to other USGS IT activities, including IT capital planning and investment control and IT security certification and accreditation.
- Provide architectural support to USGS programs and support the development of a Geospatial Modernization Blueprint for DOI.

- Implement data stewardship in support of USGS and DOI data architecture activities.

- Address requirements of OMB Memorandum M-06-02 and DOI data standardization and the Data Reference Model.

\section{Objective B: Develop and Implement a USGS Information Technology Security Plan.}

The goal of Information Technology Security is to ensure the confidentiality, availability, and integrity of USGS information technology resources. A Bureau-level information security plan is required by Congress, OMB, and DOI and is necessary to ensure that information assets (including employee data) are properly protected, that employees have reliable access to Bureau systems, and that USGS data and information continue to be reliable and available to the public. The Bureau maintains compliance with the IT security mandates in the Federal Information Security Management Act (FISMA). In accordance with the E-Government Act of 2002, Title III (Public Law 107-347), security certification and accreditation requirements are managed and maintained for the 12 major IT systems in the USGS portfolio (see Appendix II). The IT Security Management Office provides overall policy, management, and oversight for the Bureau-level information security program on all information systems.

Key tasks for FY2007-2008 include:

Security Certification and Accreditation:

- Re-certify USGS major IT systems in accordance with prescribed schedules.

- Monitor all previously certified and accredited systems to ensure ongoing compliance with Federal Information Security Management Act mandates.

- Continue to review all systems to ensure that certification and accreditation requirements are maintained and that the USGS is in full compliance with Federal laws and regulations.

\section{Security Operations:}

- Integrate penetration testing capabilities into the monthly assessment program for all IT systems to ensure potential vulnerabilities are properly classified and corrected appropriate to the threat-level. 
- Develop and implement content management technical controls to ensure that information is appropriately protected according to classification and managed in accordance with requirements for the separation of low-, medium-, and high-impact information.

- Apply enhanced IT security controls and procedures to respond to prevailing threats to the confidentiality, integrity, and availability of USGS IT systems and the information that they contain.

- Through internal scanning of IT systems, provide assurance that systems adhere to technical standards and Security Technical Implementation Guides (STIGs) and that identified vulnerabilities have been corrected.

\section{Objective C: Maintain and Improve the USGS Telecommunications Infrastructure.}

The Bureau's telecommunications infrastructure includes data, voice, video, and radio networks, each of which are needed to serve the science mission of the USGS. The industry direction is for convergence - that is, the use of one network for multiple connectivity requirements. In the near future, our local area networks (LANs) will transmit not only data but also voice and video. USGS Wide Area Networks (WANs) already support the many traffic types. Past history indicates that, in the next 5 years, traffic volumes will increase at about 20 percent per year and data rates will increase commensurately to support both new applications and the increased volumes, as will the need to integrate the technologies supporting data, voice, video, and radio. Many developments and technological advancements will occur in broadband infrastructure, high-speed LAN systems, Internet architecture, wireless communication, and mobile applications. These and other emerging technologies will be critical in improving telecommunication effectiveness, efficiency, and reliability as part of an enterprise architecture and it will be essential that the DOI Enterprise Services Network (ESN) keep pace and incorporate these technical changes to meet customer requirements. One of the key USGS telecommunications priorities for FY2007 is the continued implementation of the ESN with emphasis on both circuit enhancements and Remote Access services. At the end of FY2006, the USGS completed one of the ESN implementation steps (the three steps are connection, transition, and migration) whereby all field offices were transitioned from ESN-monitored services to ESN-managed services with full $24 \times 7 \times 365$ support.

\section{Key Tasks for FY2007-2008 include:}

- Redesign the USGS WAN by "flattening" the network from its current dual-homed architecture. Pending funding, by the end of FY2007, the USGS will have completed the third step with over 50 percent of its field offices migrated to the new network architecture.

- By mid-2007, agree to a security approach with DOI that both satisfies the DOI security requirements and meets the mission needs of the USGS and commence the implementation. Complete the Connection Approval Process when this security approach has been implemented and be formally recognized as connected (connection step) to Internet 1 services at the five DOI ESN Internet 1 Gateway nodes.

- Utilize Department Remote Access and Virtual Private Network (VPN) services to avoid duplicate expenditures and make the management of the remote access sites easier.

- Work with the DOI to institutionalize Internet 2 as a DOI service for all Bureaus. Promote the inclusion of Internet 2 as part of the DOI Working Capital Fund (WCF) in FY2008 in the ESN "base" funding.

- Establish Voice Over Internet Protocol (VOIP) as the preferred solution for USGS field offices requiring phone systems and actively work to upgrade field office LANs in order to support this converged technology. By the end of FY2008, convert over 25 percent of the phone systems with VOIP (as of the end of FY2006, this conversion was at 3 percent nationwide).

- Ensure that all telecommunications components meet the OMB IPv6 (Internet Protocol Version 6) mandate by June 2008. These components are primarily WANrelated equipment.

- Work with DOI on the Networx transition planning of voice, data, and video services to the newly awarded Networx contracts. This work includes internal DOI establishment of selection criteria, consideration of over 50 Networx services and selection, and drafting of the transition/transformation plan to the new services.

\section{Objective D: Maintain and Improve the USGS Computing Infrastructure.}

The USGS operates hundreds of servers and thousands of desktop and laptop computers across the Nation. Different parts of the organization currently provide varying levels of support (in terms of security, efficiency, and effectiveness) for these systems. Institution of Bureauwide services and solutions can meet common computer support requirements more efficiently and improve performance. Several external mandates from DOI also require the USGS to implement DOI-wide IT infrastructure solutions. Work 
under this objective will enable the USGS to achieve DOI-prescribed IT infrastructure maturity levels, as defined in the IT Infrastructure Library (ITIL), and meet current OMB objectives.

\section{Key tasks for FY2007-2008 include:}

\section{Active Directory:}

- Complete the infrastructure and science center migrations of the Active Directory construction phase. This task includes the majority of offices in the USGS.

- Complete several parallel projects related to increased IT security, consistency, and administration. These projects include an architecture redesign of Domain Name Services and an implementation of common Patch and Virus Management and common Change and Configuration Management practice using the ITIL framework.

- Continue to migrate from a decentralized, distributed IT organization to one that is consistent, highly efficient, and recorded.

\section{Electronic Messaging System:}

- Work with and on the Department Electronic Messaging System (EMS) team to ensure that the USGS e-mail and calendaring requirements are met. Begin planning and execution of a project to migrate approximately 13,000 e-mail accounts to the DOI e-mail standard.

- Begin evaluating the migration of other collaborative tools and the potential positive and negative impacts of this migration on the USGS users.

Homeland Security Presidential Directive 12:
- Pursue single sign-on capabilities using smart cards.

- Investigate the capabilities of smart cards for digitally signing official documents.

- Research replacing existing Lotus electronic forms.

- Pursue e-mail encryption in Microsoft Exchange.

\section{Objective E: Develop and Implement IT Support Services.}

New technologies, enterprise agreements, reporting requirements, and a general increase in attention to information technology have increased the challenge of accurately assessing USGS IT support needs, acquiring and managing IT equipment, and monitoring current technology developments. In addition, the increasing emphasis of DOI and $\mathrm{OMB}$ on standardizing IT practices and consolidating major IT investments can result in unforeseen restrictions in meeting the requirements of the USGS science mission. A new suite of IT support services is needed. Work under this objective will enable the USGS to achieve DOI-prescribed IT infrastructure maturity levels, as defined in the ITIL.

\section{Key tasks for FY2007-2008 include:}

- Continue to expand the IT Service Desk System to support the USGS Eastern, Central, and Western Regions.

- Broaden the scope of the Service Desk on the basis of ITIL best practices to better support internal IT services.

- Investigate alternative Service Desk software suites for possible acquisition. 


\section{Strategic Goal 2: Create the Information Management and Services Component of the Integrated Information Environment.}

The objectives supporting this goal focus on the management of information created by the USGS, including compliance with relevant Federal mandates. Achieving them will help reduce the costs and other barriers of acquiring and using USGS data and information. The Bureau has worked to increase the quality, efficiency and effectiveness of its scientific information integration and dissemination services to customers. This includes transformational improvements in libraries and public information centers, science publishing, and public web services. The development of a Natural Science Network (NSN) is the overarching objective of this goal, supported by objectives addressing the Enterprise Web, Records Management, and Publishing.

This Goal links to the following long-term goals from DOI IT Strategic Plan:

1. Information and Records Management: Create an effective knowledge-sharing environment while meeting information management standards and requirements.

2. E-Government: Improve the efficiency and effectiveness of DOI business processes.

\section{Objective A: Design, Develop, and Implement the Natural Science Network.}

The USGS NSN is evolving into a nationally integrated network of USGS information and knowledge that can be accessed in diverse ways from diverse locations and can optimize a user's personal ability to seek and obtain USGS information and products. It encompasses services provided by USGS libraries, science information centers, "Ask USGS," and a variety of USGS digital publications.

Key tasks for FY2007-2008 include:

Digital Library:

- Increase subscription services, continue to digitize holdings, acquire additional databases, purchase a link resolver.

- Retire some collections, establish a better mechanism for tracking resource uses, develop digital library plan or approach to plan, develop community of practice.

\section{Knowledge Management:}

- Build infrastructure for managing data and knowledge, develop phase 2 Frequently Asked Questions (FAQ) program, focus on electronic desktop delivery.

- Automate e-mail response, enhance web presence with portal technology.

\section{Partnerships:}

- Implement Reston Library Advisory Board, link with Central Region Library Advisory Board, develop national approach to Library Advisory Board.

- Revive the library consortium.

- Finalize and implement partnership policies with National Spatial Data Infrastructure (NSDI) Liaisons and USGS science programs.

Staffing:

- Inventory current skills, determine future skills requirements, hire national library coordinator.

- Acquire technical skills to manage digital assets, align people and functions appropriately.

- Collapse printing function in Reston Science Information and Library Services (SILS), use technicians to scan maps.

\section{Telecommunications/Metrics:}

- Enhance telecommunication/initiate call center and working relationship with infrastructure staff, develop inventory of Level 3 experts and Points of Contact (POC).

- Implement metrics.

Communications:

- Implement communications plans.

Customer Service:

- Implement the three-tier approach for inquiry response; establish SILS customer service standards.

\section{Objective B: Develop and Implement the USGS Enterprise Web (E-Web).}

The web presence of the USGS has evolved over many years as a result of the work of many authors and designers. The results are often excellent but differ in information structure, general usability, navigation strategies and tools, content quality, visual identity, accessibility, security, and other characteristics (many of which are mandated by Federal, Departmental, or Bureau policy). The Enterprise Web (E-Web) facilitates the usability, flexibility, and research value of the USGS network of public web sites through a consistent set of tools and practices that can be used across the Bureau. It will provide a common and efficient framework for relating, describing, delivering, and managing USGS web content and applications and provide a set of services designed to overcome traditional technical and organizational barriers to integrating information. It will also provide a large proportion of the software infrastructure for the NSN. 


\section{Key tasks for FY2007-2008 include:}

- Continue security planning, management, and certification and accreditation activities for the E-Web Enclave and its assets to ensure compliance with FISMA requirements and remediation of Plans of Action and Milestones (POA\&Ms).

- Collaborate with Regions to migrate existing web hosting services out of Headquarters as appropriate.

- Expand the web-hosting services of the National Web Server System (NatWeb) to enable web site consolidation, development of content management capability, and reliability during disasters.

- Develop and begin implementation of a strategy to improve the ability to search the USGS web presence.

- Develop the USGS Web Policy Handbook and ensure compliance by enhancing the web site infrastructure database and establishing the web site registration, review, and certification process.

- Establish Bureauwide web development and delivery services contracts.

- Improve the USGS homepages based on customer and stakeholder feedback.

- Provide specialized web assistance to USGS scientists and organizations, such as the Cooperative Conservation Web Site and USGS Communities of Practice.

- Update and redesign the GIO intranet site.

\section{Objective C: Establish a Bureauwide Publishing Program.}

Procedures for reviewing, publishing, storing, and reproducing science products have been developed in different ways by different organizational units within the USGS. New technologies have created opportunities to reduce the time and dollar costs of both publishing and publication storage, increase customer service, and improve responsiveness to information requests.

\section{Key tasks for FY2007-2008 include:}

- Complete the implementation of USGS Publishing Network as a High Performing Organization as outlined in plans submitted to DOI in FY2006. This includes measuring and evaluating key financial performance and quality of service against established and documented performance targets and benchmarks.
- Establish a permanent Executive Steering and Oversight Committee and an Advisory Board demonstrating a high degree of cooperation among all concerned participants.

- Establish interim funding model for FY2007 and move to a permanent model required for FY2008 and beyond.

- Develop a workforce analysis, including critical skills, for Fiscal Years 2008-2012. In the second transition year, FY2007, request and offer Voluntary Separation Incentive Payment (VSIP) in October 2006 and offer Voluntary Early Retirement Authority (VERA) throughout FY2007. Review workforce analysis annually.

- Continue technology improvements demonstrating increased staff efficiency and processing of USGS information products. Deploy and use Information Product Data System (IPDS) for processing, workflow improvements, and content management and reporting. IPDS is also used to support USGS Fundamental Science Practices by documenting peer reviews and Bureau Approvals.

- Maintain and enhance the USGS Publications Warehouse, including expansion to all reports authored by USGS personnel.

- Define and implement publishing workflow and methodology to prepare and release USGS information products. Convert software for manuscript editing, illustrating, and reports layout to standard DOI software (MS Office and Adobe Creative Suite).

\section{Objective D: Ensure Bureauwide Implementation of Information-Related Federal Laws, Regulations, and Guidelines.}

All USGS programs must comply with numerous information-related Federal laws, regulations, and guidelines that affect all aspects of program planning and implementation (see "Legislative and Regulatory Context"). Work under this objective will enable the USGS to achieve DOI-prescribed information and records management process maturity levels.

Key tasks for FY2007-2008 include:

- Plan and administer USGS programs for Privacy, FOIA, Section 508, and Information Collection that are in compliance with Federal requirements and that will enable the USGS to achieve DOI-prescribed information process maturity levels. 
- Complete actions necessary to implement the DOI FOIA Improvement Plan within USGS.

- Collaborate with USGS Science Disciplines to meet OMB Requirements for Peer Review.

\section{Objective E: Maintain and Improve a Bureauwide Records Management Program.}

USGS records management policies and procedures (based on National Archives and Records Administration and DOI directives) ensure the preservation of USGS science and administrative records in all media and document the USGS science legacy as well as its organization, functions, decisions, and essential transactions. Protecting the USGS science legacy is the critical objective of the Records Program. Work under this objective will enable the USGS to achieve DOI-prescribed information and records management process maturity levels.
Key tasks for FY2007-2008 include:

- Plan and administer the USGS Records Management program to ensure continuing compliance with Federal requirements.

- Participate in development of the DOI Electronic Records Management Plan.

- Communicate/coordinate with all USGS science and administrative programs on their records management responsibilities and activities.

- Identify and pursue opportunities to protect the USGS science legacy by conducting special records management projects throughout the Bureau as resources permit. 


\section{Strategic Goal 3: Create the Information Policy and Governance Component of the Integrated Information Environment.}

USGS processes and procedures that govern information activities are applied at all levels of the organization in all programs. New OMB and DOI directives impose additional requirements, and compliance requirements increase proportionately. Because the true costs and benefits associated with information-related activities are difficult to document, the USGS is continually revising its approach to planning and implementing these objectives, especially the information workforce objective.

This Goal links to the following long-term goals from DOI IT Strategic Plan:

1. IT Capital Planning: Improve the planning, execution and management of IT investments.

2. IT Workforce Management: Ensure the availability of IT human capital capable of meeting the goals and DOI mission challenges.

\section{Objective A: Evolve and Develop New Information Policies and Procedures.}

This objective addresses the need for more uniform, consistent, and enforced policies in several key areas. The Bureau has established processes and procedures for IT capital planning and investment control; has attained Level 2 of the GAO Information Technology Investment Management (ITIM) Maturity Model; and anticipates being at 50 percent completion of Level 3 by the beginning of FY2007.

Key tasks for FY2007-2008 include:

- Continue to lead the Bureau's IT Capital Planning efforts, including IT investments activities, and reach ITIM level 3.

- Collaboratively begin implementation of USGS Fundamental Science Practices policies.

\section{Objective B: Assess, Plan for, and Develop the Future USGS Information Workforce.}

The USGS information workforce is distributed across all science disciplines, programs, and regions. Portions of it have evolved through explicit planning, but, in many other cases, it is the result of short-term needs and the unique requirements of individual programs or projects. More information is needed about the range of current skills (including those that may be lost though retirement) and the types and numbers needed to support science and administrative programs over the next 5 years. Work under this objective will enable the USGS to achieve DOI-prescribed maturity levels as defined in the GAO Human Capital Capability Maturity Model.

Key tasks for FY2007-2008 include:

- Develop a skills-and-interest database for USGS information professionals. Consult with USGS science program staff to develop short-term (2- to 5-year) forecasts of information skills needed to support science program objectives.

- Develop a USGS Information Workforce Plan, addressing recruitment, training, retention, and relationships with colleges and universities, that reflects both traditional and evolving science information needs.

- Assess the impact of and develop, if necessary, competitive sourcing strategies for information functions.

- Participate in Federal Chief Information Officer Council IT Skills Assessment Survey.

\section{Objective C: Develop and Implement} Performance Measures for Information-Related Activities.

Requirements to document the amount of resources (funding and staffing) applied to information technology activities and to demonstrate their value through performance measures are increasing. Activities under this objective will develop a more comprehensive view of the resources used and benefits obtained.

Key tasks for FY2007-2008 include:

- Develop and implement meaningful IT performance measures.

- Complete customer identification, evaluation, and satisfaction surveys on a regular basis.

- Investigate methodologies to document benefits to customers as a result of faster, easier, and more integrated information access. 


\section{Strategic Goal 4: Create the Environmental Information Science Component of the Integrated Information Environment.}

USGS scientists face significant challenges in seeking to understand, model, and predict complex environmental systems and processes. Many of these challenges stem from the complexity, multidimensionality, and nonlinearity of the systems and processes they study and from the collection, analysis, and management of the data and information representing these systems and processes. Recognizing these challenges, the USGS identified Environmental Information Science (EIS) as one of its eight "Future Science Directions." EIS refers to the development and application of approaches that integrate natural, computer, and information sciences to address key research questions. Individual USGS scientists in different disciplines are already applying advanced information science techniques to help address specific natural science questions. Providing a Bureauwide forum for this subject and developing a long-term EIS research agenda for the Bureau can help leverage these independent ongoing activities, increase opportunities to share new techniques and approaches across science programs and disciplines, and stimulate development of new EIS research partnerships with other organizations.

This Goal supports USGS science activities under the Resource Use, Resource Protection, and Serving Communities mission areas of the DOI GPRA Strategic Plan.

\section{Objective A: Develop a Long-Term Environmental Information Science Research Agenda for the USGS.}

This activity will bring together multiple disciplines and scientists from the USGS, other DOI Bureaus, and other organizations to discuss the scope and priorities of an EIS research agenda. This objective responds to a key recommendation of the USGS EIS Future Science Direction plan.

\section{Key tasks for FY2007-2008 include:}

- Sponsor, develop, and conduct a workshop on information science and a USGS information science research agenda.

\section{Objective B: Sponsor Information Science Workshops or Conferences.}

This objective will help provide opportunities for scientists and information professionals to share information on existing EIS activities and to foster an EIS community of practice within the organization.
Key tasks for FY2007-2008 include:

- Sponsor, develop and conduct workshops on:

- Modeling (second all-USGS workshop);

- Initial planning for a second Science Information Management workshop for 2008.

- Publish Proceedings of FY2006 Science Information Management Workshop.

\section{Objective C: Develop Bureau-Level Scientific Information Infrastructure to Enhance Analysis and Modeling Capabilities.}

This objective is aimed at providing a steadily improving set of IT capabilities for professionals in the natural sciences. It will build on and leverage work already underway in individual USGS science programs, such as the Knowledge Bank in the Coastal and Marine Geology Program or the Modular Modeling activity in the Water Discipline's National Research Program. Activities under this objective will increase awareness of existing capabilities, develop consensus recommendations for development of enhanced scientific computing infrastructure, and provide automated library-like services to help facilitate the sharing of successful techniques and capabilities across projects, programs, and disciplines. These efforts will be coordinated by the EIP, in collaboration with the science programs. Target areas will evolve through this collaboration but will likely address topics such as:

- Decision Support Tools and Systems

- Integrated access to multiple distributed databases

- Modeling Infrastructure, including distributed data, models, and processing

- Digital Libraries

- Geosciences Network (GEON), Grid Computing, and High Performance Computing

- Enterprise GIS

Key tasks for FY2007-2008 include:

- Continue development of the myUSGS portal to provide assistance and support for the USGS Science Thrusts, regional projects, and science programs.

- Develop and implement Communities of Practice web site and collaboration tools.

- Develop criteria and processes to more effectively respond to field requests for assistance with integrated information planning and stewardship. 


\section{Appendix I. DOl's Response to M-06-02 Improving Public Access to and Dissemination of Government Information Using the FEA Data Reference Model}

On December 16, 2005, the Office of Management and Budget released OMB M-06-02: Improving Public Access to and Dissemination of Government Information Using the FEA Data Reference Model. The guidance indicates that "cost-effective and consistent access to and dissemination of government information is essential to promote a more citizencentered government." The memorandum identifies procedures to organize and categorize information and make it searchable across agencies to improve public access and dissemination and discusses using the Federal Enterprise Architecture Data Reference Model (DRM). Agencies must continue to review the performance and results of their information dissemination program.

In compliance with the requirements set forth in OMB M-06-02, the Department of the Interior developed the following description of its models to assist in dissemination activities and the review process.

\section{Web Component of the Department of the Interior's Information Dissemination}

\section{DOI Mission}

The U.S. Department of the Interior (DOI) protects and manages the Nation's natural resources and cultural heritage; provides scientific and other information about those resources; and honors its trust responsibilities or special commitments to American Indians, Alaska Natives, and affiliated Island Communities.

\section{Information Dissemination Across DOI Bureau}

The Department is organized into eight Bureaus and many Offices. Each fulfills one or more key elements of the DOI mission. Each Bureau disseminates information to the general public and to unique customer user communities that relate to each Bureau's mission.

The Bureau of Indian Affairs (BIA) responsibility is the administration and management of 55.7 million acres of land held in trust by the United States for American Indians, Indian tribes, and Alaska Natives. There are 561 federaly recognized tribal governments in the United States. Developing forestlands, leasing assets on these lands, directing agricultural programs, protecting water and land rights, and developing and maintaining infrastructure and economic development are all part of the agency's responsibility. In addition,
BIA provides education services to approximately 48,000 Indian students.

The Bureau of Land Management (BLM), an agency within the U.S. Department of the Interior, administers 262 million surface acres of America's public lands, located primarily in 12 Western States. The BLM sustains the health, diversity, and productivity of the public lands for the use and enjoyment of present and future generations.

The Bureau of Reclamation is the largest wholesale water supplier and the second largest producer of hydroelectric power in the United States, with operations and facilities in the 17 Western States. Its facilities also provide substantial flood control, recreation, and fish and wildlife benefits. The mission of the Bureau of Reclamation is to manage, develop, and protect water and related resources in an environmentally and economically sound manner in the interest of the American public.

The Minerals Management Service (MMS), an agency of the U.S. Department of the Interior, manages offshore oil and gas exploration as well as renewable and alternative energy sources such as wind, wave, and solar on 1.76 billion acres of the Outer Continental Shelf (OCS) while protecting the human, marine, and coastal environments. The OCS provides 30 percent of oil and 21 percent of natural gas produced domestically, and sand used for coastal restoration. MMS collects, accounts for, and disburses mineral revenues from Federal and American Indian lands, and contributes to the Land and Water Conservation Fund and other special use funds, with fiscal year 2005 disbursements of approximately \$9.9 billion and more than \$153 billion since 1982 .

The National Park Service (NPS) preserves unimpaired the natural and cultural resources and values of the national park system for the enjoyment, education, and inspiration of this and future generations. The Park Service cooperates with partners to extend the benefits of natural and cultural resource conservation and outdoor recreation throughout this country and the world.

The Office of Surface Mining (OSM) is the lead Federal agency for carrying out the mandates of the Surface Mining Control and Reclamation Act (SMCRA). The goal of SMCRA is to protect society and the environment from the adverse effects of surface coal mining operations. 
The mission of the U.S. Fish \& Wildlife Service (FWS) is to work with others to conserve, protect, and enhance fish, wildlife, and plants and their habitats for the continuing benefit of the American people.

The U.S. Geological Survey (USGS) serves the Nation by providing reliable scientific information to describe and understand the Earth; minimize loss of life and property from natural disasters; manage water, biological, energy, and mineral resources; and enhance and protect our quality of life.

There are five key goals supported by all Bureaus and Offices for which information is provided across various Bureaus and programs. These include:

- Resource Protection-Protect the Nation's natural, cultural, and heritage resources

- Resource Use-Manage resources to promote responsible use and sustain a dynamic economy

- Recreation-Provide recreation opportunities for America

- Serving Communities-Safeguard lives, property and assets, advance scientific knowledge, and improve the quality of life for communities we serve

- Management Excellence-Manage the Department to be highly skilled, accountable, modern, functionally integrated, citizen-centered and result-oriented

The DOI, comprised of its Bureaus and Offices, is committed to cost-effective and consistent access to and dissemination of government information. This is essential to promote a more citizen-centered government and accurate user-friendly information.

To achieve the goals of organizing and categorizing government information and making it searchable across agencies to improve public access and dissemination, the Department of the Interior is engaged in the following initiatives:

- DOI Web Standards Handbook - (386 DM3 HB-1) of February 21, 2006-a comprehensive document available Department-wide which establishes web standards along with organizational roles and responsibilities; requirements mandated by Federal laws and regulations, policies on authenticity and branding; document type definition standards; and customer focus.

- Taxonomy - A number of Bureaus in the Department have developed taxonomies of their information, identifying and categorizing their information into groups. These taxonomies enable the consumers of their content to more easily locate a particular type of content based on its categorization through Meta Data and enabling Key Word searches.

- RRS feeds-A number of our Bureaus and Offices have implemented RSS as a method to inform the consumers of its information on new or updated content on a real-time basis. The U.S. Geological Survey has implemented RSS for Earthquake, Landslides, and Volcano alerts greatly improving not only the availability of the information, but also the time it takes to reach the consumer.

\section{- Content Management}

- Enterprise Content Management Systems-Several Bureaus and Offices have implemented or are in the process of implementing content management systems which manage and organize web sites and web content, and make it easier for web information content providers to maintain web pages without having to learn web programming.

- Templates-Use of web page templates to promote a common interface and navigation makes it easier for users to find information on departmental web sites, i.e., they don't have to spend time "learning" a new interface.

- Implementing the Platform for Privacy Preferences Project (P3P) that enables web sites to express their privacy practices in a standard format that can be retrieved automatically and interpreted easily by user agents.

- Consumer Identification-A number of the Bureaus and Offices have conducted detailed studies to more accurately identify the consumers of their information and the needs of that consumer. This information then enables the Bureau to more accurately provide the right types of information to the right consumer through the right channel in the right amount of time.

- Web Review and Certification-An annual review of departmental web sites ensures that the public has access to up-to-date, accurate information.

- Quarterly Web Inventory Baseline

- User community Focus Groups

- Search-Key to discoverability is the consumer's ability to locate the exact type of information they are interested in. Many of the Bureaus in the Department of the Interior have invested and implemented improvement to their search engines which provide greater relevancy, increased content, and reduced search times. 
- Web site and Server Consolidation-DOI Bureaus and Offices were early adopters of the Internet and web technologies to disseminate information. Many web sites were created by content providers eager to make information available to DOI partners and the public. As technology matures, the DOI is actively consolidating and streamlining web sites to drive efficiency, reduce costs, and simplify information discovery and dissemination. Servers are also being consolidated and relocated to centralized data centers for efficiency, security, and reliability.

\section{Results of the Department of the Interior's Information Dissemination Program Review}

Information Dissemination takes place on many levels at the Department of the Interior. As noted above, the Department's broad, multi-faceted mission and geographically dispersed services and programs are responsible for maintaining and improving the Nation's natural and cultural resources, economic vitality, and community well being. Information pertaining to these programs and services is varied and our 70,000 employees and 200,000 volunteers deliver programs through partnerships and cooperative relationships that engage and invite citizens, groups, and businesses to participate. This citizen-centered approach leverages the Department's activities, which include:

- Managing one in every five acres of land in the United States.

- Operating 388 national parks and 545 national wildlife refuges.

- Managing lands and waters that generate one-third of the Nation's domestic energy supply.

- Operating over 800 dams and irrigation facilities.

- Serving American Indians, Alaska natives, and affiliated island communities.

- Providing scientific information to advance knowledge of our surroundings.

- Working with States to restore abandoned mine land sites and protect communities.

The core responsibility of the Department is to maintain the resources in its charge and to provide services to those who use or rely on them, such as: park visitors, wildlife watchers and hunters, stockmen and miners, Tribes and individual Indians, farmers, and electric power users. While the Department is committed to ensuring the public has access to the information it is entitled to under the law, we have an obligation to protect the Nation's resources in accordance with our mission. Because of the diversity of services and programs through our Bureaus, offices and mission areas information is intended to reach a variety of customers and citizens and to further the mission of each area most effectively. As a result, Bureaus are charged with managing the dissemination of this information across various channels.

Content of materials published via the internet is managed at the Bureau and office level through the web publishing schedules that maintain and control release and maintenance of information made available on the web. Web managers and the web management teams within these offices maintain the schedules, working with their Bureau organizational structure and approval levels. The web publishing schedules are maintained by each Bureau in accordance with stipulations and standards established in the Web Handbook (386 Departmental Manual DM3 HB-1, of February 21, 2006). Furthermore, material posted on the web is examined to avoid posting any non-public information on individuals. Web pages are developed with E-Government Act of 2002 privacy requirements and OMB web privacy guidelines (see OMB Memoranda M-03-22, M-00-13, and M-99-18, and Office of the Chief Information Officer (OCIO) Directives 2005-009 and 2001-001) and scanned routinely for compliance. Web scans also review compliance with Section 508 of the US Rehabilitation Act, Freedom of Information Act (FOIA) requirements, and other web maintenance standards.

With respect to quality of information standards, The Department (DOI) is in compliance with the February 2002 guidance issued by the Office Management and Budget $(\mathrm{OMB})$ requiring all Federal agencies to issue and implement Information Quality Guidelines. These guidelines ensure the quality, objectivity, utility, and integrity of information disseminated by DOI's Bureaus and offices. In compliance with the guidelines, DOI and its Bureaus and offices provide a venue for the public to challenge and seek correction of information disseminated, and Bureaus and offices have a procedure in place to address these challenges.

In addition, DOI responded to the December 2004 bulletin issued by OMB requiring all agencies to implement a system of peer review for all scientific information published in the public domain. This same bulletin issues a procedure for publishing information on the web, including a requirement that these web pages be easily recognizable and accessible to the public. DOI is in compliance with this requirement.

The Research and Development Committee that reports to the Secretary of the Interior through the Senior Science Advisor, also addresses information quality issues identified through quarterly reviews conducted by the OCIO. The Committee is composed of Bureau representatives who oversee this process on an on-going basis and work in collaboration with the OCIO and Department web manager to assure compliance. 
The Department also manages E-government projects and the information disseminated in these areas. For example, under the Recreation One-Stop program an interagency team was used to determine content to be disseminated to the public via Recreation.gov. The RecML data standard was developed through this process, which included many discussions in 1999-2003, which also involved state, local, and non-government recreation managers including two public meetings in 2002 to clarify user requirements and refine the feasibility of maintaining the data for years to come. As a result, the program offers public domain data about Federal recreation sites to everyone for re-use on other web sites and publications, focusing on accurate and consistent information about Federal recreation sites. The Recreation Information Data Base (RIDB) now offers data exchange via web services, so other organizations can access and disseminate the same data about Federal recreation sites through various other channels.

Bureaus and offices also monitor and inventory web sites, scanning for content reviews against the publication schedules established. The OCIO is responsible for developing regulations, guidelines, procedures, and coordinating standards which were developed by the Departmental Web Council (DWC). This Council has met routinely, with representation of both the Bureau Information Technology (IT) web management areas as well as representatives from the various Bureau and Departmental Office of Public Affairs as a chartered group established under the E-Government Team. The DWC provides a forum for sharing best practices, evaluating web tools and providing oversight and technical assistance for the Department's web programs, currently focusing on issues identified by the ITMC, E-gov Team, as well as general direction of the CIO.

The Office of Communications provides oversight and guidance regarding press releases and information disseminated to the public directly from the Secretary. Procedures that pertain to maintaining the continuing responsibility of keeping constituencies and the general public informed of the Department's many programs and activities (including news releases, speeches, audio visual productions, publications and articles). The overall responsibility for assuring adherence to this information posture rests with $\mathrm{OCO}$, which coordinates the general information activities of all Bureaus and Offices of the Department.

\section{Dol Plan to Reduce the Gaps in the Performance and Results of Your Information Dissemination Program}

Through this management and oversight structure, the Department Bureaus and Offices maintain the information dissemination standards established through the processes outlined above. The review processes established for each of these areas provides a means of determining gaps in performance and recommendations to address key issues. For example, the DWC currently plays an active role in addressing matters of pressing concern and bringing recommendations to the attention of the IT Management Council, E-Gov Team, and other management oversight boards for consideration. This body maintains the Web Handbook, and addresses Public Affairs concerns through the membership represented on the Council.

Bureau and Office web managers and their web management teams monitor their presence on the web through the various means noted above and conduct customer usability studies or surveys that may also highlight areas for attention or remedial action. The ITMC and other governance boards continuously review the requirements in this area as issues arise and the need for working groups or teams are required to provide guidance and ensure compliance. Bureaus maintain oversight of their information dissemination processes as noted, and are charged with compliance under the established Departmental Manual polices. Accordingly, the Department plans to continue use of scanning, inventory, compliance monitoring, and other web management techniques as well as continued oversight by the Public Affairs and business program managers over content as appropriate to maintain the performance and results in the overall information dissemination process. 


\section{Appendix II. List of USGS Major IT Systems that are Certified and Accredited}

\begin{abstract}
Advanced National Seismic System-
The USGS is modernizing and integrating its legacy seismic networks into a single Advanced National Seismic System (ANSS) and augmenting this system with critically needed strong motion monitoring of seismic energy in at-risk urban areas across the United States. The ANSS will be capable of providing real-time information on the distribution and intensity of ground shaking to emergency response officials so that they can more rapidly assess the full impact of a significant earthquake and speed disaster relief to the areas that need it most. ANSS will also provide engineers and building code developers with the information they need to improve building design standards and engineering practices to mitigate the impact of future earthquakes. A complete summary of the ANSS and associated goals can be found at: http://pubs.usgs.gov/circ/c1188/.
\end{abstract}

\section{Enterprise Web-}

The USGS Enterprise Web project is developing the capabilities necessary to ensure the availability of reliable, easily understandable and navigable secured public web sites that are carefully organized, designed, and equipped to help customers find, get, and use the USGS's vast array of natural science data and information products quickly, efficiently, and in a manner that meets their needs. It is based on a fully integrated information architecture framework and a supporting graphical design that carefully aligns USGS scientific information and applications with a suite of key common services, including search, product delivery, and customer service. Availability and fast access will be assured through development of and reliance on an underlying infrastructure of secure, failure-resistant web-hosting systems and services. In addition to its role in providing better service to customers and the public, the Enterprise Web will fully support Bureau science activities. The capabilities of the Enterprise Web include tools and techniques to better organize, describe, classify, characterize, manage, and deliver the content of some 300 web sites (containing over 500,000 "pages" of information) and 40 online databases. Several tools that either are being or have been developed will be integrated into a "tool box" to assist USGS science programs and supporting groups to upgrade their existing web sites to enterprise standards.

\section{Financial Management (USGS) -}

Financial Management (USGS) supports financial management systems by providing analysis, design, development, testing, implementation, documentation, user training, operations, maintenance, and user support. These systems include the USGS Federal Financial System (FFS) application and financial management aspects of related subsystems such as the FFS+, FFS Inventory and Fixed Assets Subsystems, and the Personnel Resources Utilization System
(PRUS) as well as interfaces between the FFS and BASIS+, FPPS, IDEAS, MAXIMO, Travel Manager, USGS Self Service Store, Space Management, Property Management, Vehicle Management and other related financial management applications, whether mainframe, networked, stand alone or web based.

\section{Infrastructure-}

Infrastructure refers to the framework of hardware, software, data, policies, procedures, and people that support the collecting, sharing, serving, delivery and archiving of information across the USGS, including, but not limited to, operating systems, databases, data interchange, network services, network management, and user interfaces. The basis for a common infrastructure is identifying core capabilities that have common applications that enable exchange of data and data formats transparently across the USGS.

\section{Inventory Property Management- \\ The Inventory Property Management security system refers to the framework of hardware, software, data, policies, procedures and staff that manage systems dealing with property for the USGS. These system track real property, rental property, and facilities and other issues pertaining to property.}

\section{Telecommunications (USGS) -}

The Telecommunications security system refers to the framework of telecommunications assets supporting the USGS mission.

\section{Landsat Ground System-}

The Landsat Project is a joint initiative of the USGS and the National Aeronautics and Space Administration (NASA) to collect and utilize images of the Earth using a series of satellites. NASA developed and launched the satellites; the USGS continues to manage flight operations, maintenance, reception, processing, archiving, and distribution of data. The primary objective of the Landsat Project is to ensure a collection of consistently calibrated imagery of the Earth's landmass, coastal boundaries, and coral reefs and to ensure that the data acquired are of maximum utility in supporting the scientific objectives of monitoring changes in the Earth's land surface and associated environment. Image data from satellites, such as the Landsat series, are one of the most efficient, cost-effective sources of essential geospatial information for the scientific and operational land and resource management communities. Image data are used to manage the Earth's natural resources, carry out national security functions, and plan many other activities of scientific, economic, and social importance, such as tracking the progress of wildland fires and changes in crop conditions. Image data are made 
available to governmental agencies and to the general public for a nominal fee via the Landsat Project web site.

\section{National Biological Information Infrastructure-}

The National Biological Information Infrastructure (NBII) is building a community of producers of reliable, high-quality biological information to support a range of consumers and a variety of uses. These biological information contributors represent all economic sectors including Federal, State, local, and tribal government agencies; academic institutions; nongovernment organizations; and private industry. The biological databases, information products, sources of biological expertise, biological resource links, and analytical tools developed and (or) maintained by NBII contributors are made available to biological information consumers for systematic discovery, organization, and storage of, and access to scientific data and information from these diverse sources.

\section{National Map Reengineering Project-}

Geographic information is an essential tool for land and natural resource management, economic and community development, and health and security services. A common set of current, accurate, and consistent basic information that describes the Earth's surface and locates features is the starting point for most geographic activities. The National Map will be a composite of continuously maintained basic geospatial data for the United States and its territories and will serve as the Nation's topographic map for the 21 st century. The National Map, which will be developed and operated through extensive, sustainable partnerships and business arrangements with other organizations, will be a data foundation to which additional data, both public and private, would be tied. It will contain sufficient detail to support national, regional, and local activities. Guaranteed availability of The National Map will allow Federal agencies to concentrate on data unique to their mission needs and avoid expending resources to find, develop, and integrate basic geospatial data each time they are needed. The proposal for The National Map Reengineering Project describes the plan to provide the information technology and infrastructure to implement the vision of The National Map in order to meet national needs for basic geospatial data.

\section{National Water Information System-}

The USGS investigates the occurrence, quantity, quality, distribution, and movement of the surface and underground waters that constitute the Nation's water resources. The National Water Information System (NWIS) is both a workflow application and a long-term database for national records of ground-water quality and levels and surfacewater quality, flow, stage and discharge. Therefore, it must be managed and maintained as a national archive of data. USGS personnel in all 50 States plus Puerto Rico and Guam use NWIS for the collection/acquisition, processing, review, storage, and dissemination of data. Data that are quickly and easily available from NWIS are essential to the implementation and successful completion of a broad range of interpretive studies addressing ground-water, surfacewater, water-quality, and water-use issues that are critical to USGS partners in local, State, tribal, and Federal government. For example, the hydrologic data stored and made available by NWIS are used not only for determining the adequacy of water supplies but also for implementing flood-warning systems; designing dams, bridges, and flood control projects; allocating irrigation water; locating sources of pollution; planning for energy development; and investigating the contamination potential of water supplies through natural and human influences. NWIS's real-time data-processing features enable data transmitted via satellite or other telemetry to be processed, screened for outliers and made publicly available from the NWIS web site 5 to 10 minutes after transmission. NWIS is a steady-state system with no expected ending date.

\section{Office Automation General-}

The Office Automation General Security system refers to the framework of hardware, software, data, policies, procedures, and people that support the desktops, virus updates, local area networks, and servers supporting the overall USGS mission.

Office Automation Specialized - The Office Automation Specialized Security system refers to the framework of hardware, software, data, policies, procedures and people that support the specialized hardware and software needed to meet special requirements of the USGS mission. 


\section{Appendix III. FY2006 USGS IT Investment Portfolio (as of August 14, 2006)}

This table shows the total USGS IT investment portfolio as of FY2006. This information is taken from the USGS portion of the Exhibit 53 for DOI. Total investment for each system is divided into Development, Modernization, and Enhancement (DME) and Steady State (SS) operations. Those systems shown in bold are major (Exhibit 300) investments (dollars in millions).

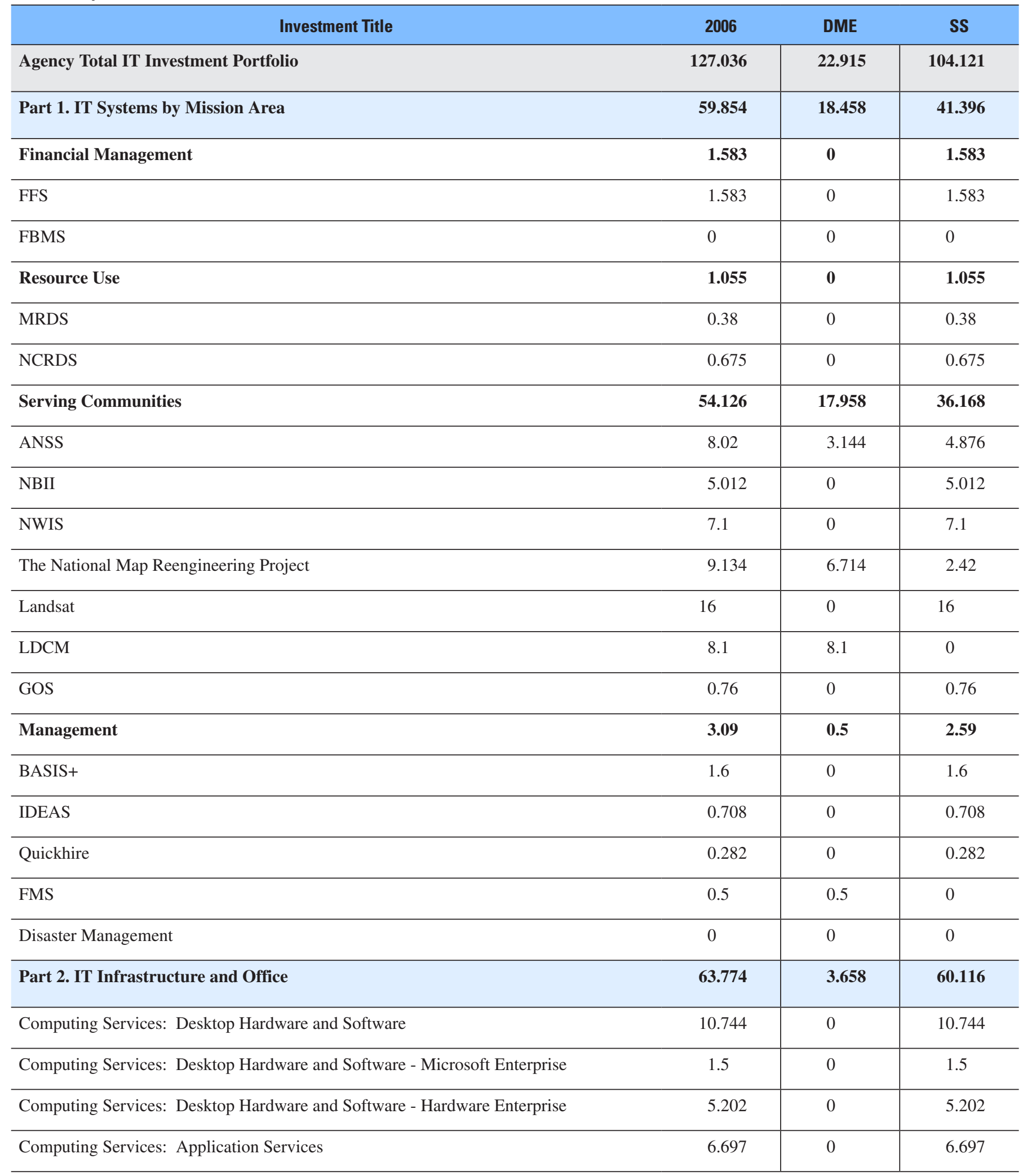




\section{Appendix III. FY2006 USGS IT Investment Portfolio (as of August 14, 2006)}

This table shows the total USGS IT investment portfolio as of FY2006. This information is taken from the USGS portion of the Exhibit 53 for DOI. Total investment for each system is divided into Development, Modernization, and Enhancement (DME) and Steady State (SS) operations. Those systems shown in bold are major (Exhibit 300) investments (dollars in millions).

\begin{tabular}{|c|c|c|c|}
\hline Investment Title & 2006 & DME & SS \\
\hline Communications Services: WAN - ESN & 2.766 & 0 & 2.766 \\
\hline Enterprise Active Directory & 1.4 & 0.4 & 1 \\
\hline Communications Services: Voice & 13.535 & 0.804 & 12.731 \\
\hline Communications Services: Video & 0.758 & 0 & 0.758 \\
\hline Cross-Cutting Categories and Services: Security - C\&A Program & 1.597 & 0 & 1.597 \\
\hline Cross-Cutting Categories and Services: Security - IT Security Program - Bureau C\&A & 0.1 & 0 & 0.1 \\
\hline E-Authentication (Partner) & 0.952 & 0.952 & 0 \\
\hline Cross-Cutting Categories and Services: Security - IT Security Program - HSPD-12 & 0.07 & 0.07 & 0 \\
\hline USGS - Cross-Cutting Categories and Services: Security - Symantec & 0.117 & 0 & 0.117 \\
\hline USGS - Cross-Cutting Categories and Services: Software Engineering - ESRI Enterprise & 1.288 & 0 & 1.288 \\
\hline USGS - Enterprise Architecture & 0.32 & 0 & 0.32 \\
\hline
\end{tabular}


